\title{
Spectra of cultural understanding: an introduction
}

\author{
David Bartosch ${ }^{1}$
}

Accepted: 13 January 2010 / Published online: 18 February 2021

(C) Academy for International Communication of Chinese Culture 2021

This special edition of International Communication of Chinese Culture bears the title "Spectra of Cultural Understanding". ${ }^{1}$ Just as the spectral decomposition of light produces seven pure unmixed colours, the theme of cultural understanding has been reflected here from seven different and genuine angles. The edition contains seven articles by distinguished international scholars from the perspective of divergent cultural backgrounds and different academic subjects and respective subtopics. Another closer look at each contribution reveals that each essay represents a certain genuine micro-spectrum in the reflection of cultural understanding in itself. For this reason, the plural "spectra" is used here to indicate a family resemblance of all seven perspectives on one hand but also their respective partial thematic autonomy in the totality of a collection of texts which is supposed to transcend habitual limits of outdated perspectives.

The sequence of texts by scholars from China, France, Germany, India, Israel, Hungary and the USA is neither supposed to imply a descending nor an ascending hierarchy. Rather, all seven contributions represent a circular concatenation of subthemes and specific perspectives on the general topic of cultural understanding. The seventh article is implicitly linked with the first again; and regardless of the different disciplinary and thematic orientations, all articles are to be thought of as adjoining and equally valued. The aforementioned family resemblance of the contributions is due to their different specific focuses on the shared general topics of culture and

\footnotetext{
1 All texts edited here have been formatted according to British spelling and punctuation standards. Exceptions are original quotations in American English. Omissions and insertions in square brackets and italics are usually by the author of the respective essay (unless otherwise noted).
}

David Bartosch

david.bartosch@hotmail.com

1 School of International Relations and Diplomacy, Beijing Foreign Studies University, Beijing, China 
understanding. The priorities of the different perspectives in relation to the general focal points of culture and understanding as well as Chinese cultural elements in particular vary in each case.

In everyday use and in the media, the term "culture" is often used without properly defining it. On the other hand, academic literature of various subjects provides us with hundreds of definitions, and there is no accepted paradigm how to define culture precisely. Intensions and extensions, if properly defined at all, vary greatly. And in various language horizons, the traditions to view culture vary as well. In the German philosophical discourse from the eighteenth to twentieth centuries for example, the German terms for "culture" and "civilisation" have been paired in several ways, and some concepts of culture with broad scopes have been developed (f. ex. by Ernst Cassirer). The situation appears to be different in English and again distinct in French and other European historical discourses, not to mention non-European conceptual histories.- - Regarding the present compilation, the first question to start with has been the following: What is the very central characteristic point of view that we can agree on here?

The present concept of culture had to allow for all the perspectives from various disciplines gathered here to be measured against it. It had to be open enough to be able to take up all the aforesaid "micro-spectra" of cultural understanding. At the same time, it must also be concise enough to be able to bring out what all these partly autonomous reflections have in common. With regard to the general concept of culture, both the Scylla of excessive over-specification and the Charybdis of conceptual arbitrariness had to be circumvented. In this sense, the guest editor of this issue decided to rest the general intension of the concept on two foundations. On the one hand, the general intension of the concept of culture should, at least in the present context, be understood as practices and processes of refinement, improvement and increasing perfection. A further specification results from the fact that, in the end, only those processes and practices may be described as "cultural" which, in view of those basic features of the conceptual intension just mentioned, do not oppose this (negated version of the) Golden Rule in addition: Don't do unto others what you don't want to be done unto you! (Today, of course, this ancient precept should also be extended to non-human life.)

If we allow for a broad extension of our concept of culture in combination with that intension then, we might start to become aware of cultural processes in almost all areas of human life. In the form of respective practices, culture is realised individually and collectively. The permanent cohesion of both sides lies in the intersubjective communication of all the actualised cultural practices. All culture is historical in this sense, either in the form of personal development or with regard to the social dimensions as such; cultural practices imply traditions perpetuating themselves over generations, and they also exist in the form of collective processes of refinement and increasing perfection, extending and fuelled by many individuals over multiple generations.

The following specific fields within the scope of our concept of culture are discussed (in the sense of the sequence of the articles): (1) language and translation, including philosophical reflections from the practice of translation in Chinese-German contexts as a basic foundation for cultural understanding, (2) the 
anthropological constant of humour as being represented in both historical Chinese and European philosophical texts and as a nexus for cross-cultural understanding throughout different traditions in general, (3) processes of culture(s) that are basically understood as the cultivation of the energetic principles which define life itself (scientific perspective) and as expressions of life (including references to pre-modern Chinese thought culture), (4) mythological narratives and calendrics approaching the very foundations of the history of Chinese cultural characteristics, (5) dialogues and mutual exchanges as reflected by anthropo-sociological cultural hermeneutics as an important aspect in the formation of cultural traditions and with regard to the communication of Chinese and Indian traditions, (6) the cultivation of emotions and representations of reciprocal transfers of Chinese and European elements in historical arts and crafts, and (7) the cultivation of mind regarding the central philosophical problem of an understanding of understanding itself and in relation to different traditions of Chinese and European philosophies (to contextualise this problem from a transcultural angle).

What's more, the seven essays do not only represent specific takes on the topic of cultural understanding in theory and in objectifying ways. They are also to be read as documents of individual realisations of cultural understanding themselves! With one exception, all of the authors are not Chinese. About half of the authors, which have been invited for this special purpose, are not experts for Chinese culture. They have used this opportunity to also actively move towards Chinese cultural elements and include them in their perspectives. Especially these texts bear witness how elements of Chinese traditional culture can be communicated and integrated in contexts where they have hitherto been underrepresented outside of China.

The first contribution to this special issue is provided by Wolfgang Kubin (b. 1945, in Celle, Germany) who is a world-renowned sinologist, one of Germany's most prolific translators as well as a renowned writer and philosophically minded poet at the same time. In China, he is known by the name Gu Bin 顾涁. He is a lifetime Professor Emeritus at Bonn University (Chinese Studies), has taught at Beijing Foreign Studies University for eight years, and has lectured at many universities all over China, in the USA and Israel. Kubin has translated approximately one hundred books from the Chinese. At present he is also a Chair Professor at Shantou University (China). Among many other high-ranking awards, he has received the VoßAward of the Academy for Language and Poetry in Darmstadt, Germany (2013) as well as the Huilin Prize for Culture (2019).

In his essay titled "Six Fragments of a Theory of Translation as Understanding" Kubin, in a pointed way, is sharing some of the most profound insights into that subject matter from the perspectives of sinology and a philosophical reflection on the problem understanding as well. As his essay is dedicated to the problem of translation and cultural understanding in the mediation of different languages (and thus also different cultural horizons), it is placed at the beginning of this compilation. Language, especially when also practiced in written form, is always at the centre of both the large-scale systems of social self-organisation in general as well as at the very foundations of the related cultural contexts and practices (which are always also open to external influences and stimuli). Living systems of language, including the enhancing and extending practices of writing, are the "gravitational forces" of 
those large-scale social systems that we also call civilisations. Language is also at the root of all the respective corresponding cultural practices. It is all those unnumerable practices of language which in every instance of communication with one's own self (we call this thinking) or others act as the all-encompassing medium that goes through everything and that holds everything together.

In his essay, Kubin addresses the problem of translation from both sinological as well as philosophical perspectives. He also turns to the German academic translation tradition. In the context of his experiences of translating complex works of Chinese literature, Kubin emphasises the importance of the translator's individual process of understanding. Translating, for example, from Chinese into German, and especially with regard to complex textual content in the fields of literature, poetry and philosophy, always bears the necessity to deal with a wide range of possibilities of understanding. Furthermore, it means to choose against the background of one's own mastery and understanding of meanings in both the source and target languages as well as one's knowledge of the "linguistic fingerprint" of the respective authors whom one is translating. According to Kubin, word-for-word translations, which are, so-to-speak, mechanically generated from dictionaries without proper contextual, linguistic and historical understanding (regarding both sides), must lead astray. Text editions can be faulty and dictionaries incomplete. To become a professional translator and intermediary of Chinese literary language, it is much more important to grasp what the author calls "the logic of the author and of a text".

The renowned French-Israeli philosopher Lydia Amir has contributed the essay "The Laughing Sage: Chinese and Western Perspectives". She is a Visiting Professor at the Department of Philosophy at Tufts University (Boston, USA). Amir has published extensively on ethics, on the history of philosophy, on humour, on the relation of theory to practice in philosophy, on meta-philosophy and on the human condition, and she has been instrumental in establishing the philosophy of humour as a new field in the humanities. The author is the Founding President of the International Association of the Philosophy of Humor and has established a new journal, the Philosophy of Humor Yearbook. Amir has published a series of monographs on the topic of humour. It might also be added that she has been a student of Ben-Ami Scharfstein. He is one of the most important pioneers in the field of transcultural comparative philosophy and aesthetics.

In the present contribution, Amir is pooling her knowledge from the fields of the philosophy of humour and from comparative philosophy to focus on the history of the reflection of humour in the philosophical traditions of Europe and China. By devoting herself to the topic of humour as well as the to related phenomenon of laughter, she is shedding a light on one of the most universal human characteristics. It is a perfect topic to be viewed at from the two different horizons of Chinese and Western Eurasian histories of philosophy. Amir starts from the Western perspective and then contrasts the former with important examples regarding an East Asian humour of wisdom. Her reflection on the general topic of the laughing philosopher - a topic which has originated due to the general image of the Greek atomist thinker Democritus, then leads to a discussion of subsequent reflections in traditional Western discourses of philosophy. Amir then turns to Chinese philosophy, thereby exploring the influence of the laughing sages of Daoism on 
Ch'an Buddhism. Based on the foundations of the general anthropological nexus of humour, Amir's contribution represents an approach to progressively expand the perspectives of Western humanities towards a more comparative and more inclusive paradigm of cultural understanding.

In the narrower sense of a culture (respectively cultivation) of emotions in forms of art, humour has always been a tried and tested means of indirectly conveying even deeper reflections and insights. And vice versa, the respective representations of laughing sages and thinkers in contexts of philosophical thinking have influenced the arts, literature and belief systems in Europe and China in fundamental (and comparable) ways. True humour is always capable of scratching at the deepest limits of understanding of the thinkable and ineffable. Therefore, it is not merely to be confused with comicality, but also represents an important aspect of the history of philosophies in East and West. With this essay, Amir introduces a promising field of cultural East-West communication and understanding. It should be explored and discussed further: That which we can laugh at intelligently and humanely rests on universal foundations-homo ridens and, in the sense of Amir's further developed conceptual approach: homo risibilis.

The Hungarian physicist, astronomer, biologist, cultural historian, musician and poet Attila Grandpierre is presenting a ground-breaking perspective on the topic "The Cosmic Roots of Human Nature and Our Culturally Conditioned Self-Image". Grandpierre has been a Senior Researcher at the Konkoly Observatory of the Hungarian Academy of Sciences from 1974 to 2013, a Visiting Professor (quantum physics and theoretical biology) at Chapman University (California, USA), and a Director of the Collective Consciousness International Research Group of the Club of Budapest for many years. He is known for his work on solar activity but also on such diverse fields as astrobiology and Eurasian cultural prehistory. Connecting the natural sciences and the humanities, he organized the conference "Astronomy and Civilization" with Paul Davies (2009), is an active member at the Institute for Ecological Civilization, and is acting as President of the Board of Trustees of the Hungarian Ecological Civilization Research Institute Foundation. As an active singer (since 1975) he has founded two legendary music groups. He won the Parallel Culture Award (2012).

Grandpierre's essay is reflecting on the questions "what life is and what reason is", and then further: "What is the Self?" To search for answers in this regard is the conditio sine qua non to "become less alienated, more living and more rational beings." At first, the author develops his topic against the scientific background of theoretical biology. One of the most important influences here is the Hungarian genius of biology Ervin Bauer (1890-1938), whose approach is still future-laden. Further philosophical implications lead the author to highlight certain parallels with basic philosophical views of ancient Chinese thought culture. In an astonishing way, these seem to be compatible with the strictly science-based outlook which the author develops very thoroughly. Everything converges on the most basic principle of biological autonomy: forms of emotional and intellectual motivation in decisionmaking processes in work-investing biological organisms. Grandpierre refers to traditional Chinese philosophy in the last part of his essay. However, the whole development of his thoughts has to be read as an important preparatory work to integrate 
those traditional elements in interpretative contexts of the modern natural sciencebased frameworks of theoretical biology and the "Life Principle", which the author is introducing in this context.

Hopefully, more philosophers, scientists and cultural theorists in China and elsewhere will discover the potential of this paradigm-shifting approach. Grandpierre's thoughts point towards a possibility to integrate traditional elements of Chinese (especially Neo-Confucian) philosophies in future forms of science-based human self-reflection in a "rejuvenating" and transformed way. The theory of the Life Principle also provides an explanation for the phenomenon of human cultures (in the sense of refinement, growing perfection and reciprocal promotion) as such. From the meta-reflective perspective of the guest editor of this issue, Grandpierre is combining elements of present-day mental culture (from theoretical biology and quantum physics) with traditional perspectives of pre-modern Chinese mental culture (ancient Chinese reflections of life). Mental culture is one of the major focus fields within the extension of the present concept of culture. From a philosophical perspective, his text not only provides a possible conceptual foundation for (inter-) cultural understanding (the author's concept of life). It also represents a practical example of how two seemingly different fields of cultural practices (modern scientific and pre-modern Neo-Confucian thinking) can be brought together in perspective of the deepest and most challenging questions of our human existence.

The anthropologist, historian and China literature specialist Robert André LaFleur has contributed the topic "Time, Space, and the Calendar in Early Chinese Mythology". The author is a US-American Professor of History and Anthropology and holds the George Russell Corlis Chair in History at Beloit College in Beloit, Wisconsin. LaFleur is a highly respected figure in the field of higher education, and he has won highly endowed teaching awards. At present, he is focusing on historical research using Chinese, Japanese, and Korean sources in combination with anthropological fieldwork on each of China's five sacred mountains. LaFleur has also been working on Chinese divinatory practices and decision-making at Erlangen University in Germany for many years. He is translating the works of the important French sinologist Marcel Granet (1884-1940). LaFleur is the lead author and editor of two very influential textbooks on China. His televised lectures on East Asian and Pacific mythology and Confucius' Analects have made him known to large audiences.

LaFleur's contribution is directing our attention to three further fields besides specific forms of language communication. These are providing further core characteristics which allow us to define a certain systemic continuity of human practices and reflections as belonging to one and the same distinctive historical-cultural process. These three fields are (1) the specific forms of the representation of time, meaning particular shared traditions in the representation of the changes of the patterns and constellations of the celestial bodies, (2) the representation of space ("the land"), and, last not least, (3) orally transmitted mythological narratives. To understand Chinese cultural characteristics from their very roots, we, amongst other things, have to start from the fact that Chinese mythology didn't set in with a creation myth but "was grounded in the temporal and spatial rhythms of the agricultural year." The resulting calendric traditions led to the formation of festival traditions which did not 
only generate the first and most basic mythical themes but also became the original backbone in the historical formation of Chinese cultural features, respectively the particular forms of representations in the cultivation of life, emotions and the mind throughout history.

In his introduction, LaFleur presents the idea that ancient spring gatherings, in combination with the narratives they were generating throughout the year as a reverberation, "created society, just as they created mythology". The author is further emphasising the role of orality for maintaining a true mythological tradition and is pointing out that the written codification is depriving mythological narratives of their original function. LaFleur presents the reader with important archetypes of Chinese myths, like the "amorous constellation" of the Herdboy and the Weaving Maiden, or Hou Ji, Lord of Millet. As one of the "the most important forces in all Chinese mythology", the former relates to the more general ancient representations of yin, yang, light and darkness, all-encompassing "movement, the flow, the gathering, and the separation" of life. After discussing the related topic of Chinese almanacs, the mythological cultural heroes $\mathrm{Fu} \mathrm{Xi}$ and Nü Gua are examined in an innovative way. In this context, rational contents come to light which are usually masked by the mythological images. By addressing the major themes of "building shared culture" and "mythical repair work", LaFleur sheds a light on the most foundational layers in the history of Chinese consciousness.

The distinguished Indian sociologist and anthropologist Ananta Kumar Giri has provided a valuable and inspiring reflection on the topic of "Cultural Understanding: Multi-topial Hermeneutics, Planetary Conversations and Dialogues with Confucianism and Vedanta". Giri is a Professor at the Madras Institute of Development Studies. His academic journey, which had begun in his home country, has led him to many, many places all over the world and then always back to India again and again. He completed his academic training in the USA and has worked as Visiting Professor or Visiting Scholar in the Netherlands, France, the UK, South Korea, Sweden, Denmark, Germany, Canada, Poland, Indonesia and Australia. In his academic studies, Giri is focusing on a broad range of topics such as: new horizons of human development and social transformations on the basis of dialogues, dignity and responsibility, criticism, creativity and the contemporary dialectics of transformations from the angle of social theory, and creative transformations in education, philosophy, literature and spirituality.

Giri's academic interests as well as his life experience are reflected in his further perception of culture as "a multi-dimensional reality and possibility regarding self, society and the world". He is emphasising that culture "does not exist in isolation". Giri is describing understanding metaphorically as "a multi-dimensional journey" including subject and object as well as "happening" in the realms of the individual self, self and other(s), cultural practices and society. Cultural and transcultural understanding thereby include a hermeneutic dimension which cannot just be reduced to textual practices. It has to include the crossing of real borders, participation in existing cultures and traditions world-wide, "walking and meditating with people".

In the major part of his essay, Giri is developing his related concept of a "multitopial" hermeneutics which is supposed to further mutual learning and cultural 
understanding across borders, because culture "does not have only roots but routes". Culture has a cross-cultural and transcultural dimension per se. From a socio-anthropological angle, the author is urging more "planetary conversations". According to Giri, these should be based on the foundations of four major discourses which have emerged during the last fifty years approximately: the ecological turn, the linguistic turn, the feminist turn, and the "onto-decolonial" turn. Giri thereby also refers to the diatopical hermeneutics of Raimon Pannikar, Heidegger's philosophical affinity for hiking, and the idea that we can implicitly maintain (and relate to) experiences from our already completed paths throughout different cultural contexts while simultaneously being able to be positioned in at least two different cultural and civilisational horizons at the same time, as he also puts it. Giri describes three hermeneutical steps which he defines as existential understanding, reconstructed cultural account, and cosmopolitan thought. The representation of a respective multi-valued logic and living has to be paired with forms of transformative critique. Crossing "Nietzsche's transcultural hermeneutics" as a theoretical bridge, Giri finally advances to the chapter "Confucianism, Vedanta and Multi-topial Hermeneutics". Reaching the apex of his reflection on cultural understanding in the end, the author points the reader towards basic comparative foundations for a necessary future dialogue of ancient Chinese and Indian traditions of thinking and living.

Anita Xiaoming Wang has a background in Chinese art and culture studies. In her essay "The Exchange of Art, Images and Artistic Techniques between China and Europe in the seventeenth and eighteenth Centuries", she is providing a substantial contribution on the topic of cultural exchange processes from the perspective of art history. Her essay also indirectly supports the thesis of the preceding text in this compilation that culture always also bears a cross-cultural aspect. Wang is a Research Associate at the Centre for Chinese Visual Arts (CCVA) at Birmingham City University in the UK. Before that she completed an Alexander von Humboldt Post-doctoral Research Fellowship in Chinese art history at the State Art Collection Dresden (SKD) in Germany. Wang is from China and has started her academic career at the Feng Jicai Institute of Literature and Art at Tianjin University, China.

In her essay, Wang is focusing on a very specific sector in the shared history of Chinese and European art. During the seventeenth and eighteenth centuries, Chinese artworks but also precious commodities, which, like in the case of Chinese porcelain, textiles, furniture, popular paintings, woodblock prints and wallpaper etc., were based on highly sophisticated production skills, left a deep impression on Europeans. With interesting repercussions on the social and cultural development in European nations of the time, local artisans and artists were imitating Chinese motifs and have thereby fused elements of contemporary Chinese and European cultural practices in the field. In general, this more specific field of interest coincides with the guest editor's meta-perspective on a wider field in the extension of the present concept of culture here. The main purpose of the arts is not instrumental or technological. At best, and apart from art theory or skill in production or performance, the creation and consumption of works of art should manifest a process of refinement and perfection of our emotional states (including cognitive add-value which the learning of an artform also entails). Even commercial (functional) artwork ought 
to meet this requirement at least on a very basic level, if it is to be subsumed under our concept of culture in general.

The author begins her historical reflection on the reciprocal representations of art elements, aesthetic forms and social connotations between China and Europe (during the seventeenth and eighteenth centuries) by shedding light on the general history of Chinese woodblock prints in Europe. These prints found admirers in the contemporary European upper class although they were disregarded by the scholarly class in China at the time. In Europe, these prints had a big influence on the style of chinoiserie. Vice versa, some artists from Suzhou started to adapt European artistic techniques "such as linear perspective, hatching and chiaroscuro". Starting from here, Wang "takes Suzhou beauty prints and Guangzhou paintings as examples to highlight the reciprocal nature of artistic exchange between Chinese and European art." In the context of exploring the influence of European artistic techniques on Chinese prints, the author turns to the depiction of female figures with shadows. After that, the European influence on Chinese painting is reflected from that angle as well. Finally, the influence of those European influenced Chinese prints in Europe is discussed. Wang emphasises that the intense contemporary economic and artistic communication of Chinese and European creators of commercial art represents a perfect example of mutual (intercultural) learning. Subsequently, this led to "the creation of new and unique styles of art".

David Bartosch has provided the essay "The Understanding of Understanding: A Philosophical Reflection from a Transcultural Perspective". He has a background in European and Chinese philosophy, with additional training in musicology and other subjects in the humanities. Currently, he works as a Contract Professor at Beijing Foreign Studies University where he is providing classes on European philosophy and on the histories and systems of Eurasian cultures and civilisations for a mixed student body from China and from all over the world. In his research, Bartosch is focusing on the systematic comparative exploration of concepts of Occidental, Oriental and Chinese thought cultures. One of the more practical questions of his research is: How can the phenomenon of culture be applied or directed to create more sustainable economic and eco-friendly output, or to foster trust and mutual learning between individuals, societies, nations and civilisations?

With his comprehensive monography "Knowing Unknowing” or "Good Knowing”? On the Philosophical Thought of Nicolaus Cusanus and Wáng Yángmíng, Bartosch has introduced the philosophy of the most important Chinese thinker of the last five hundred years, Wang Yangming (1472-1529), to a German philosophy audience for the first time. At the same time, he is keen to represent the German philosophy tradition from a more inclusive angle as well as to connect it with important contents of non-European sources world-wide, thereby also actively advancing the new field of Transcultural Philosophy (including new perspectives and methods in the history of philosophies) from the perspective of a German scholarly background.

\footnotetext{
2 The original title of the work in German is »Wissendes Nichtwissen « oder »gutes Wissen«? Zum philosophischen Denken von Nicolaus Cusanus und Wáng Yángmíng. See the bibliography of Bartosch's essay in the present issue.
} 
In addition to philosophy, the author has also lectured in interdisciplinary contexts ranging from linguistics, cultural studies, musicology to cultural diplomacy, and he has performed research tasks at many universities in Germany and China. As a renowned expert in the field of cultural theory and East-West cultural dialogue, he has been interviewed for television, other media formats, and has also appeared in several award-winning documentary films.

In his present article, Bartosch is posing the following central philosophical question: What is understanding? He begins with an analysis of the literal meaning behind the second word component of the English word "understanding" ("-standing"). The reflection is interwoven with basic anthropological reflections by the philosophers Aristotle and J. G. Herder, and finally with anthropo-cosmic foundations of the ancient Confucian classic Liji. The further etymology-related analysis of the prior word component of the English term ("under-") is complemented by an extension of the transcultural approach. After that, the whole expression is explored in the sense of a philosophical metaphor, and Kongzi, Martin Heidegger, Plato and Zhuangzi are consulted in that context from a transcultural angle. His analysis of the inherent philosophical semantics of the German terms "Verstehen" and "Verstand" (as translations for "understanding") enables the author to further clarify the initial question. Based on that, a subsequent analysis of comparable thoughts from the Chinese Confucian-Daoist tradition makes references to the Daodejing and to Wang Yangming's philosophy in particular. The article aims to suggest that the self-referential quest for an understanding of understanding points to the most fundamental and unifying transcultural layers of human existence. 